Orbis Tertius, vol. XXIV, $\mathrm{n}^{\circ}$ 30, e140, noviembre 2019-abril 2020. ISSN 1851-7811

Universidad Nacional de La Plata

Facultad de Humanidades y Ciencias de la Educación

Centro de Estudios deeoría y Crítica Literaria

\title{
Javier Gasparri, Néstor Perlongher: por una política sexual. Rosario, FHumyAR, 2017, 162 páginas $^{1}$
}

En el vocabulario de la teoría feminista, los estudios gays y lesbianos, la teoría queer, la disidencia sexual y LGTBQ es un lugar común mencionar y hacer uso de un canon prefijado de autores, en su gran mayoría provenientes del norte global. Estos son la pastoral queer, Judith Butler, Paul B. Preciado, John Scott, Monique Wittig, Simone de Beauvoir, Donna Haraway, Jack Halberstam, entre otros. Ante esta mirada previamente canonizada y extensamente difundida, suele reclamarse lo propio ante lo ajeno, lo nacional ante lo foráneo (suerte de afán provinciano), o mejor aún, los recorridos específicos y situados en contextos sociohistóricos frente a cajas de herramientas globales o de una pretendida aplicabilidad universal, sin ningún lugar de anclaje.

Como decíamos, volviendo al juego de dicotomías, un punto de partida desfasado suele ser empezar desde otras genealogías, herencias y legados. En ese otro espacio, un locus 'sudaca' y latinoamericano, se ubica Néstor Perlongher por una política sexual de Javier Gasparri publicado por la Editorial de la Facultad de Humanidades y Artes de la Universidad Nacional de Rosario. Mucho antes que la teoría performativa del género de Judith Butler, las críticas queer al estado liberal democrático y su capacidad fagocitadora de toda repulsividad política en políticas identitarias y la captación mercantil de las identidades gay o la crítica a las normas de parentesco heterosexual detrás del matrimonio igualitario, - y en esto no soy nada original, ya lo decía Brad Epps (2008) ("Retos, riesgos, pautas y promesas de la teoría queer")—; mucho antes del activismo queer y luego su reconocimiento académico o la gloria queer en departamentos de universidades norteamericanas, un ensayista, poeta y activista argentino, Néstor Perlongher manchaba de tinta, semen y otros fluidos, escribía páginas sobre el neobarroso rioplatense, la deformidad y radicalidad de Lamborghini, o sobre la ritualidad performática del 'yire' en San Pablo o incluso la resignificación del insulto y la injuria. Y por mucho antes no quiero señalar con el dedo en alto la novedad oculta en un tiempo previo, o ese afán por lo propio y nacional, sino más bien por la singularidad epistemológica de Perlongher, es decir, el entrelazamiento y superposición de sus análisis literarios, ensayísticos, sexuales y políticos.

Pero antes que señalar el punto temporal antecesor de Perlongher respecto de la teoría queer ("Perlongher estuvo antes que Butler"), operación que aún mantiene como centro de referencia a la teoría angloeuropea, lo que resulta más productivo e interesante de la lectura de Gasparri es, desde el inicio, la recepción que hacemos de Perlongher hoy. El valor de una caja de herramientas no queda necesariamente anulado por la conciencia crítica de su especificidad histórica y sus límites culturales, suerte de correspondencia morfológica entre contexto y teoría, o entre situacionalidad socio-histórica y su construcción analítica. Pero los conceptos feministas de género, de la teoría queer y la disidencia sexual plantean de forma aguda los problemas de comparación cultural, de traducción lingüística y de solidaridad política.

A través de ese desfase temporal nos llega el libro de Javier, publicado en 2017. Nos llega luego del impacto de la teoría queer y de la disidencia sexual pero también y más aún, luego de la canonización de nuestros autores y autoras, de la recepción local de Perlongher en distintas áreas de la crítica. Toda edición implica una anacronía, dice Luciano Lamberti (en revista Crisis, Octubre-Noviembre de 2018): en principio podemos pensar en 
qué dice y cómo funciona una obra fuera de su contexto, la repetición de ciertos temas en el espíritu de la época y la comprobación de que el contexto es, a veces, nada más que eso, y que los problemas que plantea una novela están más cerca de la sensibilidad del autor o de sus razones biográficas (p. 1).

Una pregunta es transversal, entonces, al texto de Javier ¿de qué modo nos interpela el Perlongher de Gasparrien ese desfase temporal que le es constitutivo? ¿Cuál es su anacrónica contemporaneidad? ¿Por qué Perlongher sigue siendo un autor contemporáneo a nuestro tiempo? Y hagamos más explícita la pregunta, ¿a qué nos convoca Perlongher hoy, a qué nos convoca Néstor Perlongher: Por una política sexual de Javier Gasparri hoy?

El trabajo de Javier se abre paso, desde el inicio, ante dos tentaciones: primero, el biografema, recurso de larga tradición, hacer de Perlongher (alias Rosa L. de Grossman o Victor Bosh) un reflejo de su vida y su obra un reflejo mimético de su vida. Este modo de narrar hace de la escritura de una obra una refracción o un registro de las vivencias del autor. En el caso de Néstor Perlongher: Por una politica sexual hace del recurso biográfico una caja de resonancias de la obra de Perlongher en relación a un clima de época y según nos recuerda Javier, esa relación ha sido en Perlongher siempre incómoda, de un claro desfasaje. Su itinerario es sabido, formó parte de diversos grupos pioneros en los activismos y militancias feministas y de la disidencia sexual: el grupo Eros del FLH (Frente de Liberación Homosexual), el grupo de Estudio y Práctica Sexual en los primeros años de la década del setenta, las feministas Unión Feminista Argentina y el Movimiento de Liberación Feminista, se acercó y alejó del peronismo de izquierda, leyó las resonancias del Gay Power estadounidense post-stonewall (el Gay Liberation Front) junto con el Frente Homosexual de Acción Revolucionaria francés post Mayo del 68 (con Guy Hocquenghem a la cabeza).

En segunda instancia, caer en la tentación de la recepción más popular de Perlongher, su poema emblema de la posdictadura, Cadáveres. Aunque Gasparri cae, en alguna medida, en esta tentación, no lo hace de un modo directo porque Cadáveres resuena como telón de fondo que reaparece en distintos capítulos.

A pesar de esta vía de tentaciones, el camino de Néstor Perlongher: Por una política sexual es otro. El texto de Javier se centra en la obra de Perlongher a partir de esa pregunta que funciona como trasfondo: ¿cuál es la actualidad de la obra pero también del procedimiento-Perlongher hoy? ¿Cuál es, en otros términos, la potencia actual e imperecedera de Perlongher? El punto de partida, que se lee en el encabezado del título, es por una politica sexual, dimensión constitutivamente política de la sexualidad en cuyo centro de irradiación el deseo y el goce sexual atraviesan todos los órdenes de la vida. Política sexual, deseo y goce que Perlongher pone tempranamente a circular en la década de los setenta y que luego se volverá expansiva hasta entrada la década del noventa; una política sexual, del deseo y el goce que logra efectos de reverberación que continúan y que, de algún modo, aún conserva su aliento.

Este libro gira en torno (y le da vueltas y contra-sentidos giratorios) a un desobediente y un provocador, antihumanista de izquierda y anarcolibertario, un incómodo a su tiempo. Gasparri nos advierte (o más bien nos alienta), a releer a contrapelo esos gestos corrosivos e incómodos de una obra y sus respectivos procedimientos formales, estéticos y estilísticos. Entonces, de nuevo, reiteremos la pregunta, ¿̇cuál es esa politica sexual anunciada por Perlongher en un tiempo presente, desfasado, corrido y anacrónico, un tiempo presente marcado por la inflexión neoliberal y neoconservadora pero también un tiempo-presente pos matrimonio igualitario, ley de identidad de género y adopción? O, en otros términos, ¿cuál es el locus (el espacio y el lugar) de la incomodidad y la desobediencia sexo-política pero también de la intervención crítica y poética?

Para quien pregunta de qué va la cosa y no aguantan que la cosa vaya como si fuera a ningún lado, como girando sobre sí. Para calmar la ansiedad que estos merodeos provocan, retomemos el índice que compone el texto de Javier. En términos formales Néstor Perlongher: Por una politica sexual se estructura en cuatro capítulos temáticos y es el tercer capítulo, en particular, el que funciona a modo de bisagra porque además de vincular lo anterior y lo sucesivo, es donde Javier construye un nudo de imantación conceptual. Gasparri rastrea tres escenas de la obra de Perlongher que se constituyen en tres entradas, tres movimientos 
y oscilaciones que no responden estrictamente a la historización cronológica, pero que dan cuenta de tres registros de la obra de Perlongher, el ensayo, la poesía y la escritura epistolar; se trata de tres niveles de análisis, el intelectual, el literario y el político, tres formas heterogéneas que se miden en torno al eje magnético de la política sexual o la sexo-política que, luego veremos, es también una sexo-poética-política, una política de la lengua o una poética-política (y así todos los sintagmas y neologismos posibles que le caben a una obra tan creativa como singular). Los capítulos, ejes, entradas y movimientos que componen Néstor Perlongher: Por una politica sexual son pares reversibles, complementarios y superpuestos, pueden leerse, en este sentido, intercalados y salteados. El trabajo de Gasparri logra componer una analítica crítica que, sin resignar a la estilización del trabajo conceptual (una poética y una cadencia muy singular atraviesan el libro), se cifra a partir del trabajo con material de archivo consultado (los manuscritos, papeles personales y textos inéditos) de Perlongher en la Universidad Estadual de Campinas y el Centro de Documentación Cultural Alexandre Eulalio (CEDAE) en San Pablo. Pero la indagación de Javier no se conforma con el recurso archivístico y filológico (si se nos permite la expresión) sino que atraviesa los espesos campos de la crítica cultural, desde la teoría de la recepción, el análisis hermenéutico de la poesía, una suerte de sociología del campo intelectual, la teoría de la lectura y finalmente, el análisis comparado de cartas.

Así, los capítulos de este arco son, Un sitio para la polémica intelectual capítulo inicial donde Gasparri indaga sobre el Perlongher-polemista, ensayista y disidente sexual a partir de su intervención sobre la guerra de Malvinas en la revista Sitio. En esta primera entrada leemos a un Perlongher que ironiza ante la toma de posición moralizante y solemne de Ramón Alcalde, Jorge Jinkis, Luis Gusmán y Eduardo Grüner en el número 2 de la extinta revista Sitio. La crítica mordaz y paroxista de Perlongher, luego recopilada en Prosa Plebeya (1997), marca una serie de respuestas que se miden en torno a la legitimidad discursiva entre locales y exiliados y que luego se tematiza como el discurso del exilio. En el caso del autor de La ilusión de las islas, se trata del exilio sexual "pero a la manera de esos exilios microscópicos, moleculares: la gente se va solita, o en pequeños grupos, sin asumir su condición de exiliados” escribe Perlongher (2004).

En el segundo capítulo, Austria-Hungria: una violencia sexopolitica, la partitura nos conduce a un movimiento que va desde la poética a la política y de allí a la sexualidad, lo que es decir, a partir de una lectura minuciosa (con lupa de joyero digamos) del poemario Austria-Hungría, Gasparri subraya esa voluntad de Perlongher de hacer vibrar las fibras sensibles de “eso que está pasando". En sintonía con Pier Paolo Passolini, ese aire marica de familia (o mejor esa filiación marica) que Gasparri rastrea, a partir de la mescolanza entre política y eros, Perlongher busca dar cuenta de una representación sexualizada del horror y el genocidio que Gasparri denomina sexopolítica. Y ese gesto vincula también a Perlongher con su ex-compañero del FLH Manuel Puig, sexualizar el horror y erotizar la solemnidad de la izquierda, gesto que se lee en El beso de la mujer araña publicado en 1976.

Capacidad corrosiva de intervenir, se trata de "irrumpir en el llamado discurso social, que a veces es muy aburrido” escribe Perlongher. La violencia política que se descubre sexualmente en Perlongher funciona como un operador crítico que retrata, mediante ensoñaciones poéticas, la carne viva, la perforación de los cuerpos, que captura imágenes más crudas del horror. La experiencia del horror, la tematización poética del terrorismo de estado o la Guerra de Malvinas, son barro mediante el cual el poeta encuentra analogías o más aún, una poesía del materialismo ensoñado como "alucinación y delirio poético que busca intervenir". Ante el horror y los sueños de exterminio, recordemos la Guerra de Malvinas, el terrorismo de estado, la eugenesia social contra maricas, trans y disidentes o incluso el "yire" homosexual en los setenta en el radio céntrico porteño, es corroída desde adentro, la violencia ejercida sexualmente "en y sobre la carne es cuestionada en su fuerza por algún rodeo del goce” (p. 67), lo que es decir, eso que me hacés para exterminarme de algún modo me gusta.

En este punto de futuro anterior o futuro próximo, en aquello de antecesor de Perlongher que hoy leemos a través de lo dicho y escrito por la pastoral queer, Javier anota un recurso sumamente potente para nuestros presentes. A propósito de Austria-Hungría, dos movimientos son recurrentes a lo largo del poemario. Anota 
Gasparri, la sodomización del verdugo (primero) y el dolor que destila una posibilidad del goce (segundo), pueden pensarse alrededor de la antiparastasis, esto es, la devolución invertida del insulto o daño. Lo que leemos en Judith Butler como resignificación y reapropiación performativa del insulto y la injuria, en el Perlongher de Gasparri es la aceptación e incluso el festejo de algo que hace daño. La figura de la antiparastasis que proviene del ámbito jurídico implica la aceptación de los términos para luego invertirlos; dicha inversión supone el cambio de valor de los términos y/o su devolución al interlocutor. El uso de un léxico es, en la sexopoiética (sexo-política-poesía que recuerda a la poesis y la capacidad de creación) de Perlongher, una operación cultural sexo-disidente, es decir, términos que habiendo sido acuñados como injurias o estigmas se les cambia el valor y se los invierte. Loca, puto, marica, tortillera, queer, sodomita, todos estos son insultos reapropiados afirmativamente y en un tono festivo. Pero también, aclara Javier en una extensa nota al pie la antiparastasis en griego designa los "preparativos de resistencia, colocarse en orden de batalla, rebelarse, resistir" (nota 29).

Barro, barroso, desplazamiento que va de la dureza a la viscoso, de lo sólido a lo terroso húmedo, de allí que la poética-sexual de Perlongher se ubica, de nuevo en la pregunta por el locus, la espacialidad y la ubicación de un autor, un autor fuera de serie (la suya es una escritura alejada de cualquier retórica o imaginario bienpensante). Gasparri encuentra una teoría de la estética-política que gira en torno al archi-conocido tema del rol social de los poetas-artistas (o su tan aclamado 'compromiso social'), pero que no obstante en Perlongher se arrastra al barro acuoso de sus versos, tal como lo destaca Jorge Panesi (2000). La política de la lengua de Perlongher se ubica en una zona barrosa y untuosa entre lo elegíaco-metafísico y el lloriqueo social. La irrupción antisolemne de Perlongher se ubica entre Osvaldo Lamborghini y Juan Gelman o de otro modo, en un legado que le es aún más cómodo, entre el niño proletario, boquitas pintadas y los Tadheys, o releído contemporáneamente, diríamos que Perlongher se ubica entre la lengua travesti de Marlene Wayar y Naty Menstrual, su amiga marica chilena Pedro Lemebel, el mexicano Carlos Monsiváis, la matriarca feminista María Moreno y la chonga neuquina Vale Flores.

La tercera entrada, Sexualidad y saber: buisqueda ensayistica y emergencia intelectual, se inaugura con un hallazgo:

En un ejemplar de La voluntad de saber, primer tomo de la Historia de la sexualidad de Foucault, que se encuentra en la Biblioteca del Instituto de Filosofía y Ciencias Humanas de la Universidad Estadual de Campinas, leemos en la última página: 'final angustiante'. El ejemplar, según indica un sello que también tiene otros tantos libros de los estantes de sexualidad y género, perteneció a Néstor Perlongher (p. 77).

En el método, en la cadencia de la escritura (amable y cuidadosa), con un trasfondo poético en la propia tinta de Gasparri, en el método, decíamos se revela una política del detalle, una política de lo menor, una política de lo secundario, lo lateral e ínfimo. Trabajo de garimpeiro, su metodología garimparia procede, como lo indica el verbo portugués, por selección meticulosa de extracción de lo valeroso, quien encuentra un diamante, plata u oro en el barro. Como la anotación "final angustiante" que descubre en La voluntad de saber de Foucault. Mirada atenta a lo minúsculo que se revela en ese gesto detectivesco que lee en la última página de un libro una frase, un libro entre tantos otros en el estante de la biblioteca. Entonces, desde la política poética a la poética sexual podemos agregar, releyendo a Perlongher a pelo y a contrapelo, desde los grandes tópicos la mirada se agudiza, la lectura se exhibe sexualmente en los detalles, en los breteles para Puig, en "un prendedorcito descolgado", en "mangas acaloradas de la mujer", o "en la lingüita de ese zapato que se lía disimuladamente”. Atención minuciosa al detalle, micropolítica de lo efímero, micropolítica del acercamiento singular, micropolítica de las cosas, materialismo o mejor manierismo poético de los cuerpos. Trabajo de archivo y mirada atenta (close reading). Ese método-Gasparri apunta a la lectura de Perlongher y sus fuentes: Michel Foucault, Deleuze, Guattari, Freud y Marcuse pero también las fuentes literarias Severo Sarduy, Góngora, Lezama Lima, Allen Ginsberg y Osvaldo Lamborghini. Lectura disidente, corrosiva y queer de Perlongher sobre el sexo y sus límites, que apuesta a la indeterminación y maleabilidad constitutiva de la sexualidad, el goce y el deseo, como escribe Gasparri, "corrosión genérica de los límites 
heteronormativos entre lo masculino y lo femenino". Es decir, Perlongher afirma una política poética de la disidencia sexual contra la cristalización identitaria (identidad nacional e identidad sexual) y sus esencialismos más inmovilizantes pero también ante la experiencia de la censura, el silencio y el horror de la dictadura. En este contexto, lo que emerge es la lengua de la loca, lengua de un barroco de trincheras porque esa política de la lengua neobarrosa, de una lengua dentro de otra lengua (escribe Spinoza) o una política deslenguada (apunta Vale Flores) es aquella que le permite decir aquello que no se puede decir.

La sexopolítica barrosa de Perlongher se conjuga como un espacio libertario de corrosión de límites, se trata de un gesto que horada eso que contemporáneamente y en un tono de tibieza llamamos 'deconstruir' o 'deconstruirse' en relación a los mandatos de género que parece reducirse a la voluntad psicologizante y subjetiva de los sujetos. La lengua deslenguada de Perlongher, la sexopolítica barrosa de trinchera, interpela en su radicalidad ese gesto tímido del 'deconstuirse' y apuesta, precisamente, al sistema sexo-genérico completo porque es este el que tiene que corroerse y reiventarse.

En esta tercera entrada descubrimos también a un Perlongher aburrido y tedioso en el rol que le ocupa como intelectual, ya sea en su campo académico, las postales de provocación militante y sus intervenciones de ensayista polemista, o en la imagen ante los ojos de los miches (los prostitutos masculinos de San Pablo con quienes se involucra) que lo ubican en el estereotipo letrado del "profesor". Por eso, la figuración intelectual de Perlongher es la de un incómodo e inconformista, lejos del humanismo y su clave moral de compromiso en los años setenta y ochenta, digamos, no encaja en la solemnidad de la discusión intelectual "anteojuda" ya sea del denuncialismo ejemplar de Rodolfo Walsh o el semblante densamente serio de David Viñas. No obstante, las intervenciones sin ceño fruncido de Perlongher no se relegan al mero y craso anti-intelectualismo. Antes bien "su palabra poética es escrita con seriedad microscópica" (p. 87), lo que inaugura, entonces, una figuración emergente e inaudita de la posición del intelectual.

Por último, en el cuarto movimiento, titulado Un dolor de abandono. El relato del sida en las cartas a Sara Torres, lo que se figura es un programa a futuro. Aquí Javier anota los saberes sobre el sida que Perlongher escribe en sus últimas cartas a Sara Torres. Un programa a futuro porque en este último movimiento del libro se exhibe una zona poco explorada en Perlongher, la dimensión vulnerable y expuesta de su corporalidad en la experiencia de la enfermedad y la inminencia próxima de la muerte. Pero un programa a futuro también, porque puede ponerse en serie con los estudios sobre enfermedad de Alicia Vaggione en Escrituras sobre sida en América Latina (2013) o el número de la revista Informe escaleno dedicado a pensar enfermedad, entre tantos otros.

Finalmente, el aporte decisivo de Gasparri es, y allí radica su intelligentsia como crítico, una crítica poética de trinchera. En efecto, se trata de leer las tematizaciones sexodisidentes de Perlongher (el qué piensa) en conjunto con las operaciones formales, estéticas y culturales (el cómo escribe eso que piensa) y en simultáneo con su registro analítico, aquello que encuentra al escribirlo "que no estaba entre sus planes y hasta dónde puede llegar con sus proposiciones o hasta dónde puede llevar mediante la escritura” (p. 112). Así, insistiendo sobre lo dicho (en círculos concéntricos que vuelven sobre sí) la analítica crítica de Perlongher pero de Gasparri en el trabajo sobre Perlongher también, está íntimamente vinculada a su poética y su ensayística. Y esa es también la poética de trinchera de Gasparri, una crítica rosarina de la disidencia que hace de la crítica una poética-política en la escucha de que lee y en su revés complementario, una política de la lectura que es capaz de escuchar al que escribe.

Repitamos las preguntas iniciales, por última vez, ¿de qué modo nos interpela el Perlongher de Gasparri? ¿Cuál es su anacrónica contemporaneidad, por qué Perlongher sigue siendo un autor contemporáneo a nuestro tiempo? ¿A qué nos convoca Perlongher hoy, a qué nos convoca Néstor Perlongher: Por una politica sexual de Javier Gasparri hoy? ¿Cuál es la actualidad de la obra pero también del procedimiento-Perlongher hoy? ¿Cuál es, en otros términos, la potencia inactual e imperecedera de Perlongher? Ese es el Perlongher de Gasparri, en un futuro próximo y un futuro anterior a la pastoral queer pero también a nuestro tiempo presente y — vale la insistencia - la poética barroca procede por antiparastasis, es decir, nos prepara en el arte 
de la resistencia, nos coloca y nos desplaza en orden de batalla, para rebelarse y resistir. Y esa es una prueba de que los temas nunca se cierran, las trincheras nunca acaban del todo y de que los problemas siguen siendo ásperos, más allá de los contextos precisos y el espíritu específico de la época.

Martin De Mauro Rucovsky

\section{REFERENCIAS BIBLIOGRÁFICAS}

Perlongher, N. (2004). Papeles insumisos. Ciudad Autónoma de Buenos Aires, Argentina: Santiago Arcos.

\section{Notas}

1 Se publica la presentación del libro de Javier Gasparri en el marco del 50 Congreso de Género y Sociedad, en Casa Laberinto, en la ciudad de Córdoba el día 21 de Septiembre de 2018. 